\title{
Avaliação do Conforto Urbano Sob a Influência da Vegetação na Cidade de Cuiabá - MT
}

\section{Urban Comfort Assessment Under the Influence of Vegetation in Cuiabá City - MT}

\author{
${ }^{1}$ AllyfKumakura Alves, ${ }^{1}$ Andressa Tainara Campelo de Jesus, ${ }^{1}$ Kaira Cristina de Macêdo, ${ }^{2}$ Mariza de Mello \\ Arruda Sampaio \\ ${ }^{1}$ Aluno de Graduação em Engenharia Civil da Faculdade de Arquitetura Engenharia e Tecnologia - FAET \\ Universidade Federal de Mato Grosso /UFMT(makurallyf@ hotmail.com) \\ ${ }^{2}$ Professora Doutora no Departamento de Arquitetura e Urbanismo-FAET/UFMT
}

\begin{abstract}
RESUMO: A questão do conforto térmico é um assunto muito importante, visto que a cada dia as cidades estão crescendo e com o avanço da urbanização aumentam as ilhas de calor. A presença de vegetação no espaço urbano contribui para a redução do desconforto térmico. O presente artigo apresenta uma pesquisa realizada em Cuiabá, no estado de Mato Grosso, em que procura relacionar o aumento ou diminuição da vegetação em determinados pontos da cidade, contribuíram para a variação da temperatura local.
\end{abstract}

Palavras-chave: Vegetação, Conforto, Temperatura, Calor.

\begin{abstract}
The question of thermal comfort is a very important issue, because every day cities are growing and advancing urbanization increase the heat islands. The presence of vegetation in urban space contributes to the reduction of thermal discomfort. This article presents a survey conducted in Cuiaba, in Mato Grosso, which seeks to relate the increase or decrease of the vegetation in some areas of the city contributed to the change in local temperature.

Keywords: Vegetation, Comfort, Temperature, Heat.
\end{abstract}

\section{INTRODUÇÃO}

O desafio das grandes cidades é o crescimento e o desenvolvimento urbano que proporcionem geração de riqueza, qualidade de vida e qualidade ambiental para seus atuais e futuros habitantes. Esse é o princípio do desenvolvimento sustentável, o qual estabelece o meio ambiente como ponto comum e de equilíbrio entre a tecnologia e o progresso, na escala onde a vida acontece: o espaço urbano. (ARAUJO, CARAM, 2006).

Segundo Menon, Leung e Chunho (2008) as ilhas de calor urbano são consideradas um dos principais problemas do século 21 como resultado da urbanização e industrialização das civilizações humanas. O problema torna-se pior em cidades ou metrópoles com grande quantidade populacional e atividades econômicas extensivas.

Segundo Bertello (2004), ilha de calor é: fenômeno típico das cidades, onde a falta de circulação atmosférica e de vegetação, somada a grandes extensões de concreto, provoca um aumento de temperatura no meio urbano. Em algumas cidades brasileiras o fenômeno pode ser observado com um agravante: a concentração de poluentes pode intensificar as chuvas ácidas e os efeitos da inversão térmica. (BERTELLO, 2004)

$\mathrm{O}$ crescimento desordenado das cidades brasileiras e as consequências geradas pela falta de planejamento urbano despertaram a atenção de planejadores e da população no sentido de se perceber a vegetação como componente necessário ao espaço urbano. Dessa forma, mais expressivamente, a arborização passou a ser vista nas cidades como importante elemento natural atuando como reestruturador do espaço urbano, pois as áreas bastantes arborizadas apresentam uma aproximação maior das condições ambientais normais em relação ao meio urbano que apresenta, entre outros, temperaturas mais elevadas, particularmente, nas áreas de 
elevados índices de construção e desprovidas de cobertura vegetal (CARVALHO, 1982, p. 63).

Entende-se por arborização urbana toda cobertura vegetal de porte arbóreo existente nas cidades. Essa vegetação ocupa, basicamente, três espaços distintos: as áreas livres de uso público e potencialmente coletivas, as áreas livres particulares e acompanhando o sistema viário. (EMBRAPA, 2000).

Estudo da Universidade de Campinas (UNICAMP) comprovou que algumas espécies arbóreas utilizadas na arborização urbana reduzem bastante os efeitos da radiação solar e oferecem conforto térmico ao ambiente.

\section{ÁREA DE ESTUDO}

Localizada no centro-oeste do Brasil, no estado de Mato Grosso a cidade de Cuiabá fica no centro geodésico da América do Sul, entre as coordenadas geográficas de $15^{\circ} 35^{\prime} 56^{\prime}$, latitude sul e $56^{\circ} 06^{\prime} 01^{\prime}$ ' longitude oeste. A cidade está na margem esquerda do rio que possui o mesmo nome da cidade. (IPDU,2007).

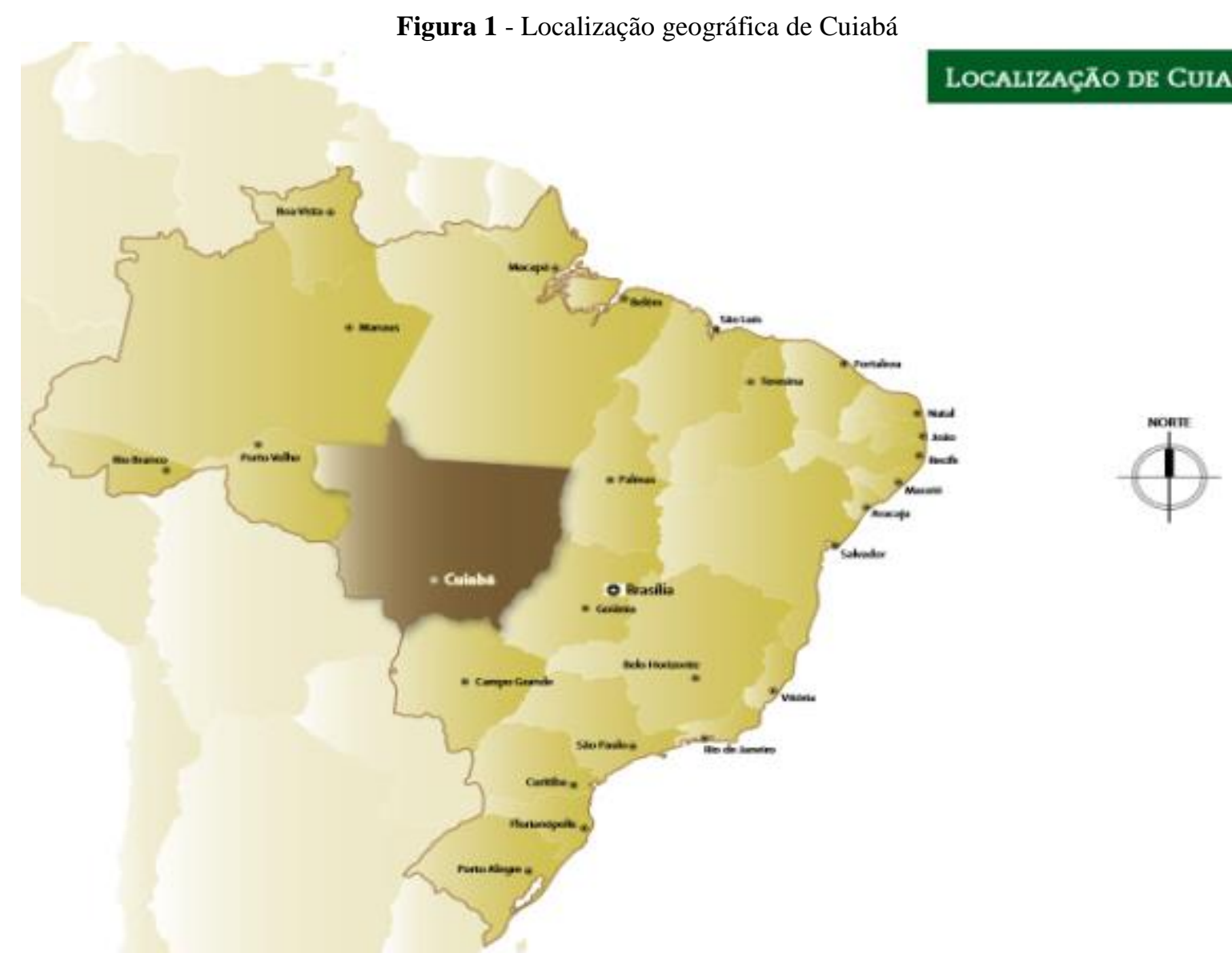

Fonte:http://www.cuiaba.mt.gov.br/upload/arquivo/perfil_socioeconomico_de_cuiaba_Vol_IIIpdf 
Figura 2 - Regiões administrativas de Cuiabá

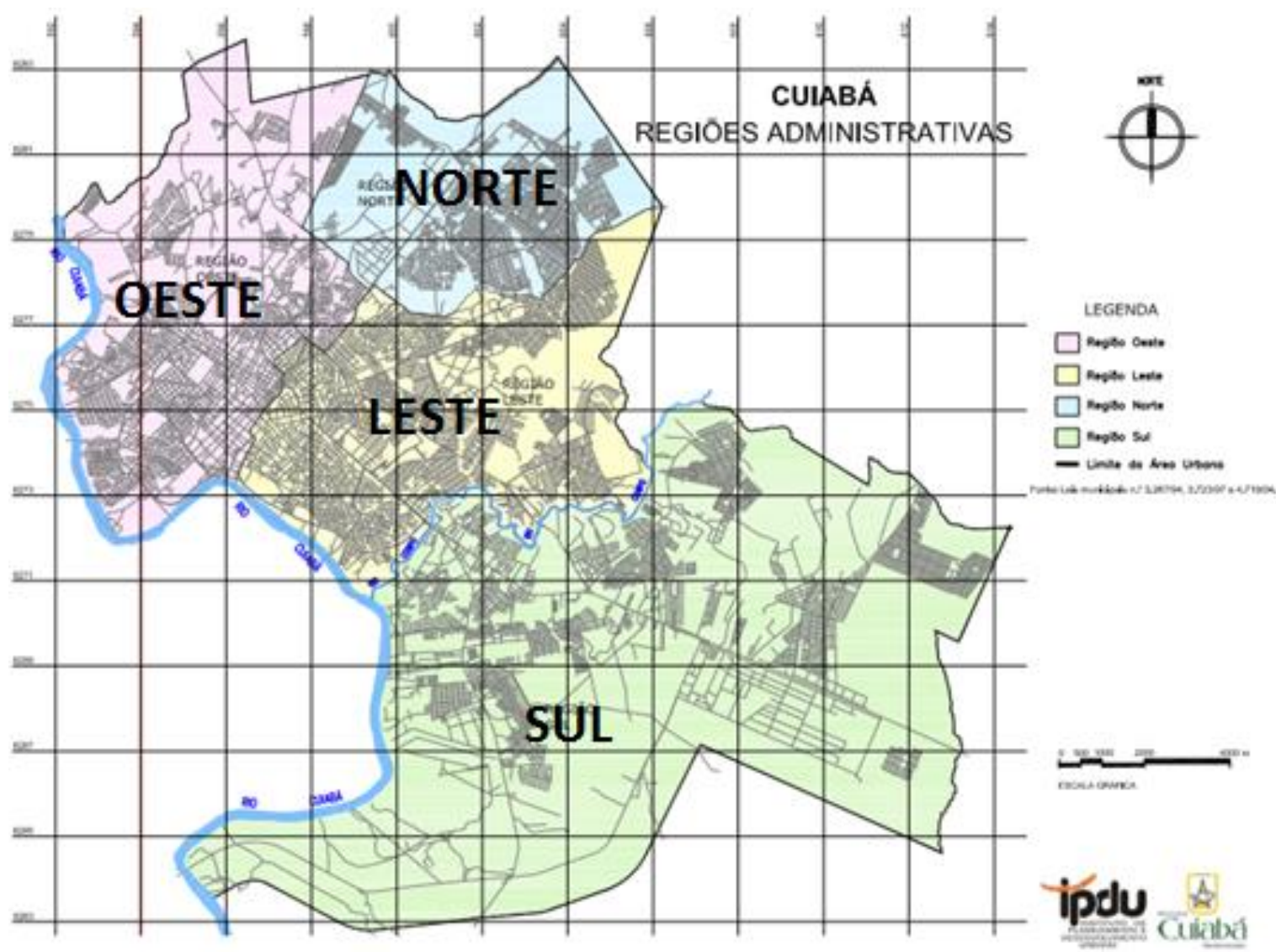

Fonte:http://www.cuiaba.mt.gov.br/upload/arquivo/perfil_socioeconomico_de_cuiaba_Vol_IIIpdf

A população da cidade era de 551.098 habitantes em 2010. A cidade forma uma conurbação com o município vizinho Várzea Grande, totalizando uma população de aproximadamente 800.000 habitantes no aglomerado urbano (IBGE,2010).

De acordo com a classificação climática de Köppen e Geiger, o clima da cidade de Cuiabá é classificado como Aw. O clima da cidade é classificado essencialmente como Tropical Continental, mas com algumas variantes típicas do lugar, apresentando dois períodos distintos: o chuvoso, com duração de oito meses, e o seco, com duração de quatro. Cuiabá tem uma temperatura média máxima de $32,7^{\circ} \mathrm{C}$, média mínima de $21,4^{\circ} \mathrm{C}$ e $1469,4 \mathrm{~mm}$ é a pluviosidade média anual. (IPDU,2007)

A distribuição de chuvas é tipicamente de clima tropical, onde no verão tem o seu máximo e no inverno o clima é seco. Cerca de $70 \%$ das chuvas são acumuladas entre os meses de novembro e março. Por isso, Cuiabá é conhecida hoje como a capital brasileira mais quente (MAITELLI, 1994).

Segundo MAITELLI (1994) o crescimento urbano em Cuiabá-MT influenciou o aumento da temperatura mínima média, com tendência de elevação de $0,073^{\circ} \mathrm{C}$ por ano analisado com dados do período de 1970 a 1992, período que coincide com a intensificação do crescimento populacional. 
Alves A. K.; Jesus A. T. C. de; Macêdo K. C. de; Sampaio M. de M. A.; Avaliação do Conforto Urbano Sob a Influência da Vegetação na Cidade de Cuiabá - MT. E\&S - Engineering and Science, (2017), 6:1.

Tabela 3- Variações climatológicas observadas na cidade de Cuiabá no período de 1970-2002

\begin{tabular}{|c|c|c|c|c|c|}
\hline \multirow[t]{2}{*}{ Meses } & \multicolumn{3}{|c|}{ Temperatura do $\operatorname{ar}^{\circ} \mathrm{C}$} & \multirow[b]{2}{*}{$\begin{array}{c}\text { Unidade Relativa } \\
\text { Média }(\%)\end{array}$} & \multirow[b]{2}{*}{$\begin{array}{c}\text { Totais Médios de } \\
\text { Chuvas }(\mathrm{mm})\end{array}$} \\
\hline & $\begin{array}{l}\text { Média das } \\
\text { Máx. }\end{array}$ & $\begin{array}{l}\text { Média da } \\
\text { Mín. }\end{array}$ & $\begin{array}{l}\text { Média } \\
\text { Comp. }\end{array}$ & & \\
\hline Jan. & 32,7 & 23,4 & 26,8 & 81 & 215,4 \\
\hline Fev. & 32,6 & 23,1 & 26,4 & 83 & 218,4 \\
\hline Mar. & 32,3 & 23,4 & 26,6 & 82 & 221,8 \\
\hline Abr. & 32,8 & 22,6 & 26,2 & 81 & 134,8 \\
\hline Mai. & 31,6 & 20,2 & 24,6 & 79 & 57,4 \\
\hline Jun. & 30,9 & 18,0 & 23,2 & 76 & 24,1 \\
\hline Jul. & 31,8 & 16,7 & 23,0 & 69 & 10,7 \\
\hline Ago. & 33,8 & 18,5 & 24,9 & 64 & 18,5 \\
\hline Set. & 34,0 & 21,3 & 26,3 & 67 & 67,0 \\
\hline Out. & 34,1 & 23,0 & 27,6 & 70 & 117,2 \\
\hline Nov. & 33,3 & 23,2 & 27,2 & 76 & 183,2 \\
\hline Dez. & 32,7 & 23,5 & 26,9 & 80 & 200,9 \\
\hline Médias & 32,7 & 21,4 & 25,8 & 76 & 1469,4 \\
\hline
\end{tabular}

Fonte: $9^{\circ}$ Distrito de Meteorologia - INMET. Dados Trabalhados no Laboratório de Climatologia. Departamento de Geografia/UFMT

Na região da baixada cuiabana o bioma predominante é o cerrado (IPDU, 2007). As áreas periféricas da cidade são dominadas pela vegetação de cerrado, com árvores de 4 metros de altura, caule e ramos retorcidos; suberosos, folhas ceriáceas, com copas que se tocam e cerradão, tipo vegetacional florestal de cerrado, com árvores de 8 metros de altura e copas entrelaçadas. A mata ciliar acompanha os corpos d'água e tem árvores com 10 metros de altura. A mata semidecídua e a mata de encosta, com espécies arbóreas com estratos contínuos de 10 metros de altura ocorrem mescladas aos demais tipos de vegetação e nas áreas de relevo mais acentuado. Assim, as vegetações nativas da região e espécies remanescentes do cerrado formam um verdadeiro cinturão verde em torno da área urbanizada de Cuiabá (GUARIM 1990).

Foram escolhidos três pontos para a coleta de dados, de forma que pudesse ser avaliada a variação térmica em vários pontos da cidade. Os pontos escolhidos ficam nas regiões administrativas oeste, norte e leste da cidade de Cuiabá (Ver figura 2).

Neste contexto, é fundamental que uma cidade que registra com frequência altas temperaturas como Cuiabá, encontre alternativas para minimizar o desconforto térmico sofrido pelos cidadãos no espaço urbano. Com este intuito, o presente trabalho visa demonstrar a importância e os efeitos positivos da arborização urbana, de forma que haja uma conscientização da população e uma atenção especial do poder público acerca deste assunto.

De maneira geral, grande parte da sociedade atual percebe a necessidade da criação e manutenção de alternativas legislativas que minimizem os impactos ambientais e térmicos trazidos pelo crescimento urbano. (SAMPAIO, 2015)

\section{MATERIAL E MÉTODOS}

A pesquisa baseou-se em um método muito utilizado em estudos de variação de temperatura que é o método teórico experimental.

Monteiro (1976 e 1990), Oke (1982) e Katzshner (1997) apresentaram proposições metodológicas, que resultou no desenvolvimento mapas urbanos e relacionou as temperaturas com o uso e ocupação do solo. Tomando como base estas relações, esta pesquisa foi desenvolvida. 
A pesquisa possibilita analisar as diferenças microclimáticas que ocorreram ao longo de 10 anos e a possível relação com a vegetação local. A coleta de dados foi realizada com medidas fixas.

Na obtenção das variáveis microclimáticas em 2013/2014foram utilizados registros obtidos pela Estação Meteorológica do Aeroporto Marechal Rondon (disponível em www.wunderground.com), situada na cidade de Várzea Grande, vizinha à Cuiabá. Também utilizou-se dados da estação micrometeorológica localizada na Av. Beira Rio. De ambos os pontos foram coletados dados de temperatura do $\operatorname{ar}\left(\mathrm{T}^{\circ} \mathrm{C}\right)$ e umidade relativa (UR\%).

$\mathrm{Na}$ correção dos dados de temperatura e umidade, foram utilizados os valores médios diários de duas Estações Meteorológicas no período de medições. Em seguida, foi feita a verificação estatística por meio de duas amostras em par para médias, denominado Teste-t.

Os dados coletados tanto de 2003/04 quanto os de 2013/14 foi organizado em gráficos, que contém a umidade relativa do ar e a temperatura média de dez meses do ano.

São apresentadas as imagens da região de coleta de dados, e imagens de satélite com marcação do local com descrição de algumas características do bairro e/ou avenida para melhor compreensão.

Os pontos foram escolhidos de forma que coincidissem com alguns dos pontos do trabalho realizado em 2003/04 pelo grupo de pesquisa em geografia da Universidade Federal de Mato Grosso, e que fosse possível avaliar as diferentes regiões da cidade de Cuiabá.

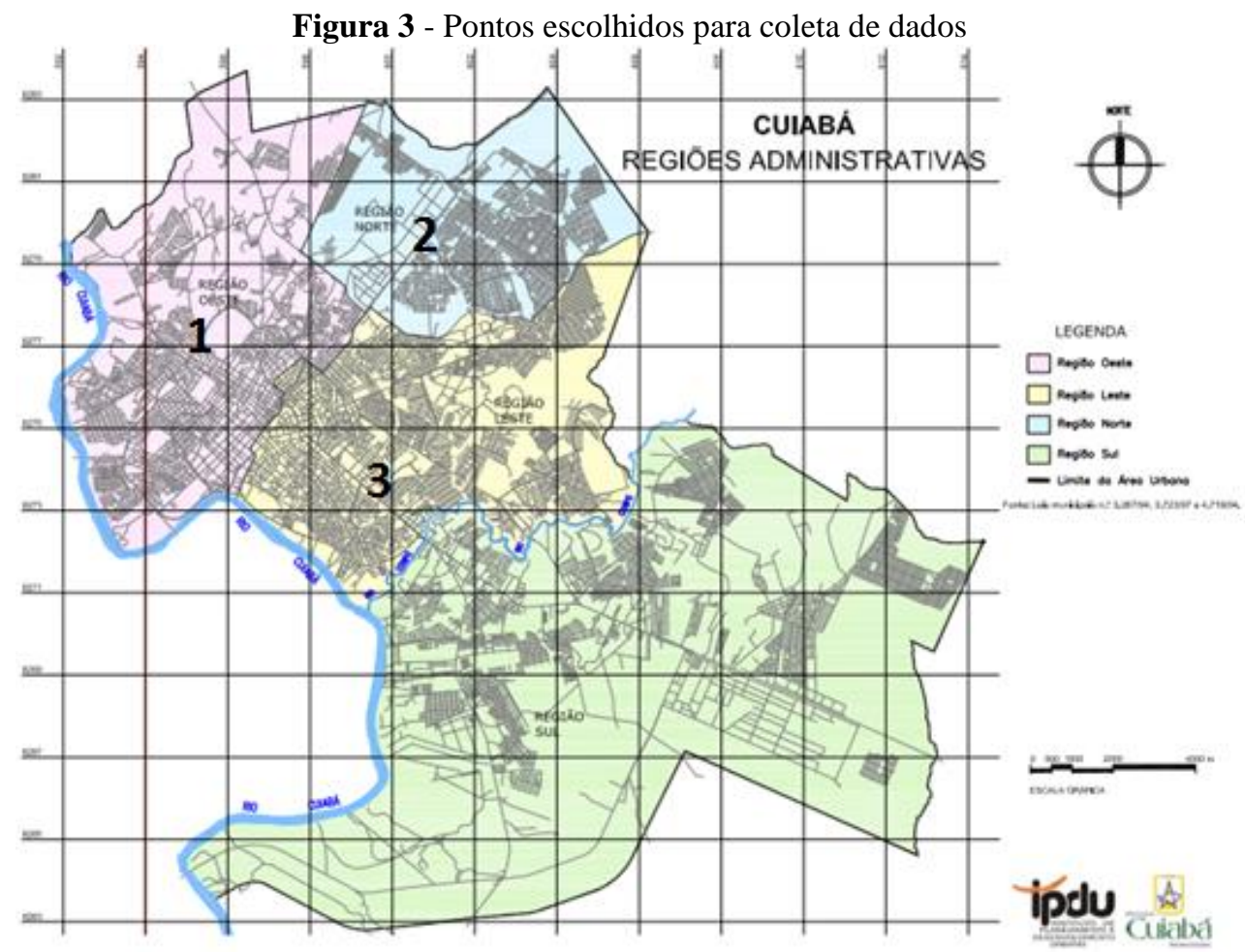

Fonte:http://www.cuiaba.mt.gov.br/upload/arquivo/perfil_socioeconomico_de_cuiaba_Vol_III.pdf

\section{RESULTADOS E DISCUSSÕES}

\section{Ponto 1 (Oeste)}

O ponto 1 fica em uma área nobre com concentração de diversos edifícios residenciais. Está localizado na Avenida Antártica na rotatória com a avenida Miguel Sutil, e avenida Lavapés, em uma região próxima à área central da cidade. 
No entorno não existem grandes áreas verdes, porém os canteiros centrais das avenidas próximas ao ponto são arborizados. Nos últimos anos se iniciou a obra de uma trincheira visando uma melhor mobilidade urbana, o que causou a retirada de algumas vegetações das redondezas (Ver figuras de 4 a 7 ).

O local fica próximo à área central e no encontro de avenidas importantes da cidade de Cuiabá. Além disso, concentra alguns edifícios comerciais, inclusive um shopping.

Figura 4 - Ponto 1, Zona oeste, próximo ao bairro Santa Rosa em 2004

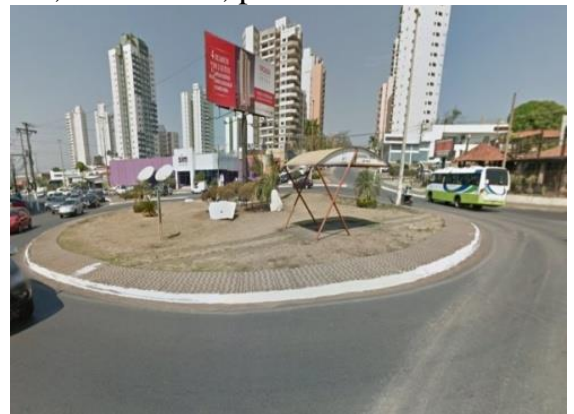

Fonte: Google Earth (acesso em 2016)

Figura 5- Ponto 1, Zona oeste, próximo ao bairro Santa Rosa em 2004

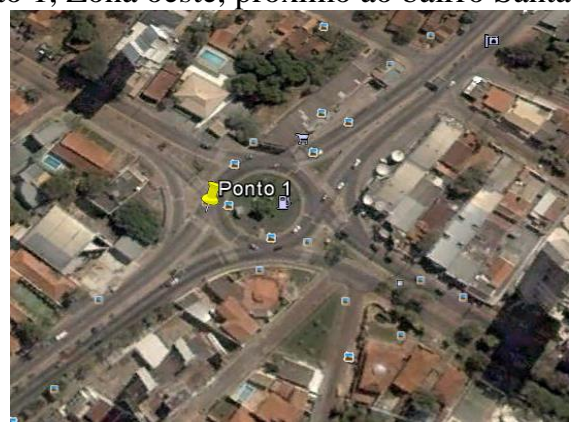

Fonte: Google Earth (acesso em 2016)

Figura 6- Ponto 1, Zona oeste, próximo ao bairro Santa Rosa em 2014

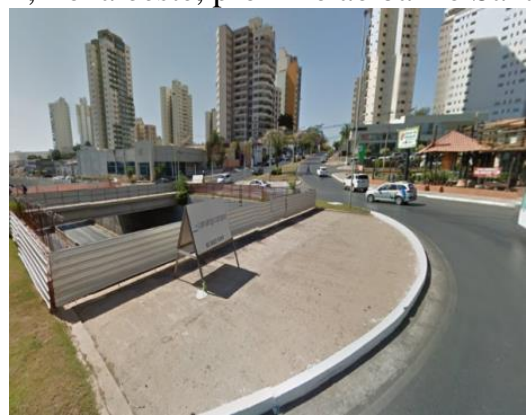

Fonte: Google Earth (acesso em 2016)

Figura 7- Ponto 1, Zona oeste, próximo ao bairro Santa Rosa em 2014

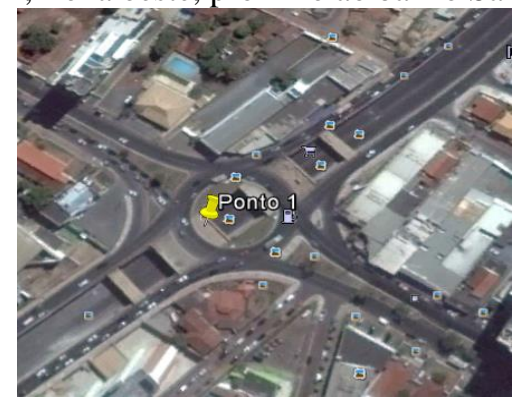

Fonte: Google Earth (acesso em 2016) 
Alves A. K.; Jesus A. T. C. de; Macêdo K. C. de; Sampaio M. de M. A.; Avaliação do Conforto Urbano Sob a Influência da Vegetação na Cidade de Cuiabá - MT. E\&S - Engineering and Science, (2017), 6:1.

Gráfico 1 -Ponto 1(8 horas) - relação temperatura x umidade 2003/04 e 2013/14

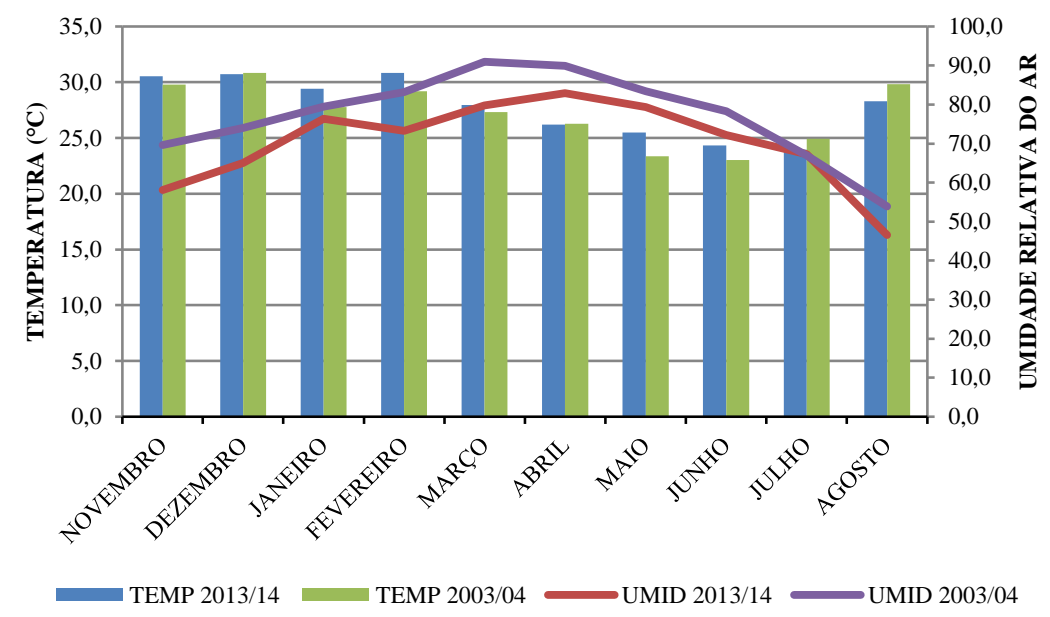

Gráfico 2 -Ponto 1(14 horas) - relação temperatura x umidade 2003/04 e 2013/14

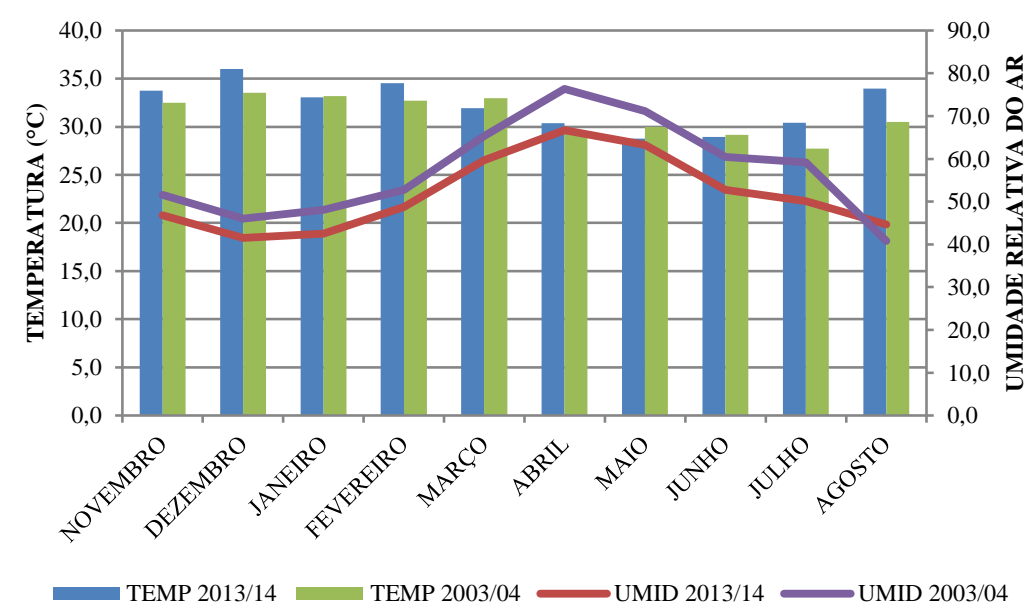

Gráfico 3 -Ponto 1(20 horas) - relação temperatura x umidade 2003/04 e 2013/14

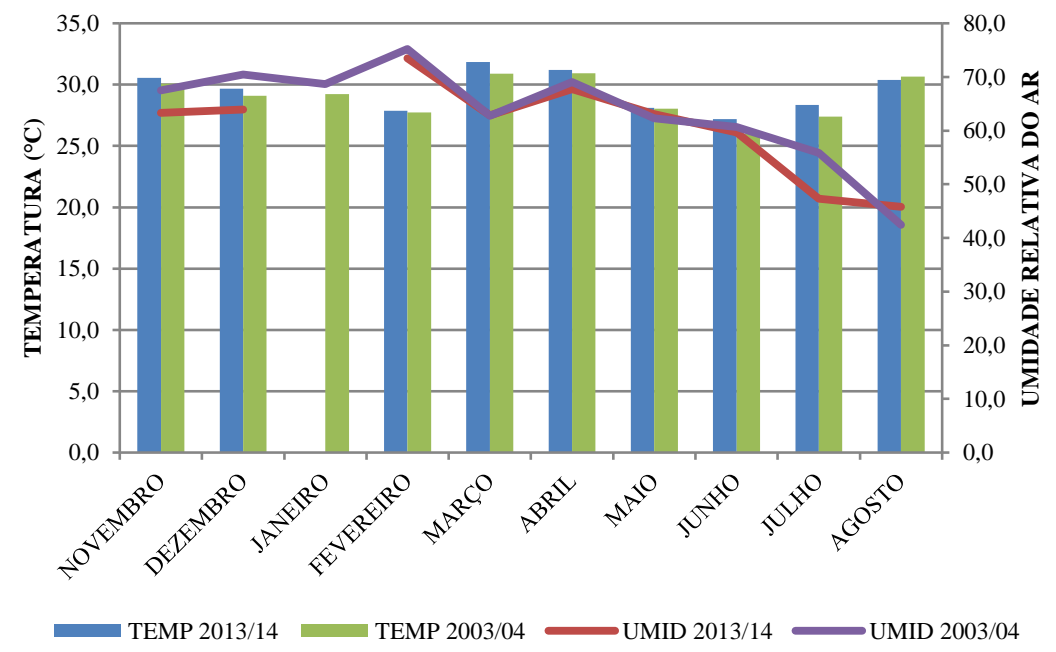


Percebe-se pelos gráficos 1, 2 e 3 que a temperatura aumentou ao longo dos dez anos nesta região. Segundo os dados coletados, a temperatura média anual subiu de $29,1^{\circ} \mathrm{C}$ para $30,0^{\circ} \mathrm{C}$, o que representa um acréscimo de $0,9^{\circ} \mathrm{C}$. A maior variação foi registrada no período vespertino (14:00h) com acréscimo de $1,2^{\circ} \mathrm{C}$.

No período de seca, foi registrada uma das maiores variações na umidade do ar. Nos dados coletados às 14 horas no mês de junho de 2004 a média da umidade foi de $62,4 \%$ enquanto que no mesmo período de 2014 foi registrado a média de 51,1\%, uma queda de $11,3 \%$.

Como esta região apresenta uma grande concentração de edifícios, se torna difícil a implantação de grandes áreas verdes, logo deve-se pensar em alternativas que integrem as edificações com as vegetações.

Quando os conflitos, em determinado espaço urbano, tornam-se muito evidentes, faz-se necessária uma análise para se revitalizar esse espaço, criando um ambiente que integre o meio às novas expectativas sócio-culturais e funcionais, para então surgir um novo espaço paisagístico com elevado grau de legitimidade, o que melhoraria, sem dúvida, a qualidade de vida da população (BONAMETTI, 2001)

\section{Ponto 2 (Norte)}

O ponto 2 está localizado na Avenida Historiador Rubens de Mendonça (Avenida do CPA) próximo ao Parque Estadual Massairo Okamura. Perto do local de medição existem poucas construções, fazendo com que haja bastante área permeável. As vegetações das redondezas pouco se alteraram ao longo dos anos, exceto o canteiro central que perdeu boa parte das arvores existentes (Ver figuras de 8 a 11).

A avenida é a principal via de acesso ao centro da cidade para quem mora na região norte, uma das regiões mais populosas de Cuiabá, fazendo com que haja um maior fluxo de veículos no período de início da manhã e fim de tarde, começo e fim do horário comercial.

Figura 8- Ponto 2-Avenida Historiador Rubens de Mendonça em 2004

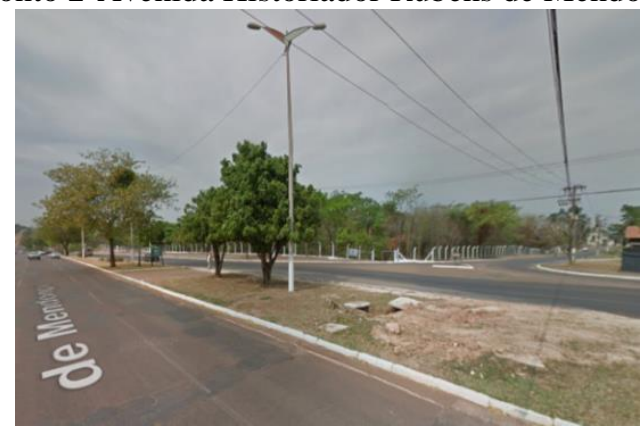

Fonte: Google Earth (acesso em 2016)

Figura 9- Ponto 2-Avenida Historiador Rubens de Mendonça em 2004

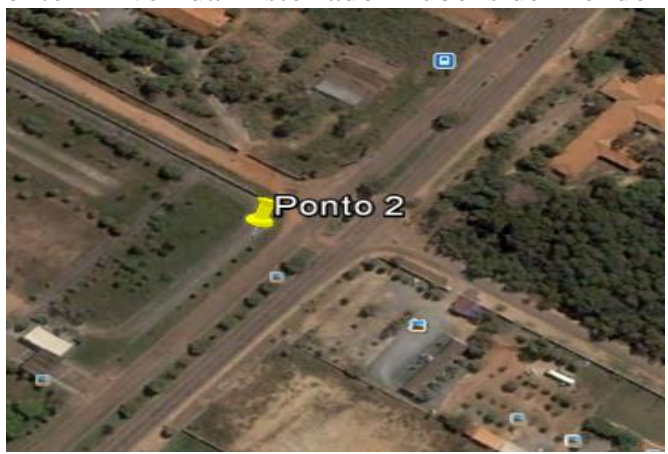

Fonte: Google Earth (acesso em 2016) 
Alves A. K.; Jesus A. T. C. de; Macêdo K. C. de; Sampaio M. de M. A.; Avaliação do Conforto Urbano Sob a Influência da Vegetação na Cidade de Cuiabá - MT. E\&S - Engineering and Science, (2017), 6:1.

Figura 10- Ponto 2-Avenida Historiador Rubens de Mendonça em 2014

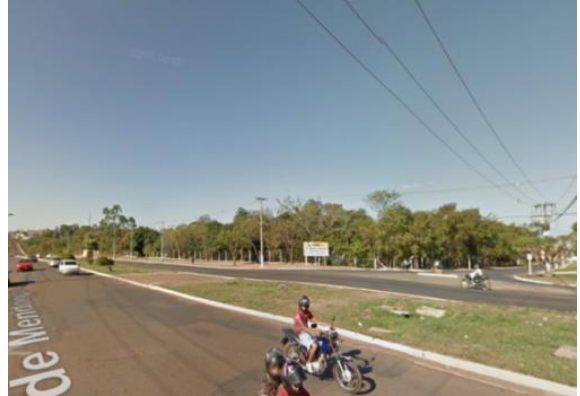

Fonte: Google Earth (acesso em 2016)

Figura 11- Ponto 2-Avenida Historiador Rubens de Mendonça em 2014

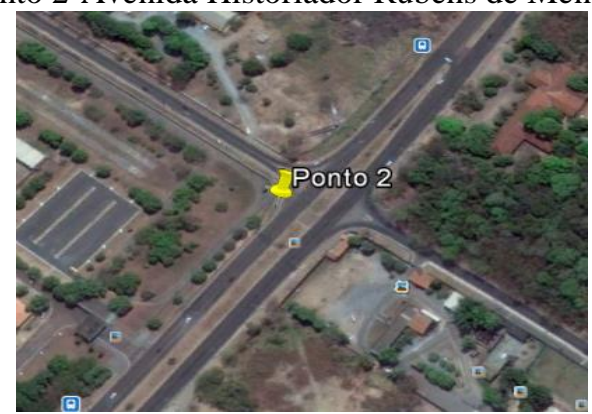

Fonte: Google Earth (acesso em 2016)

Gráfico 4 -Ponto 2 (8 horas) - relação temperatura x umidade 2003/04 e 2013/14

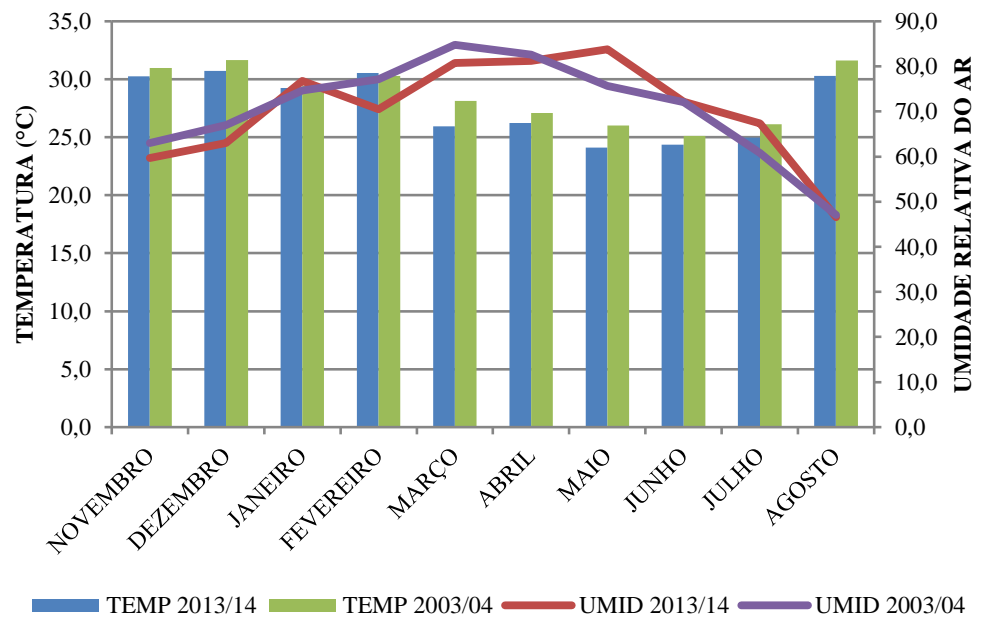

Gráfico 5 -Ponto 2 (14 horas) - relação temperatura x umidade 2003/04 e 2013/14

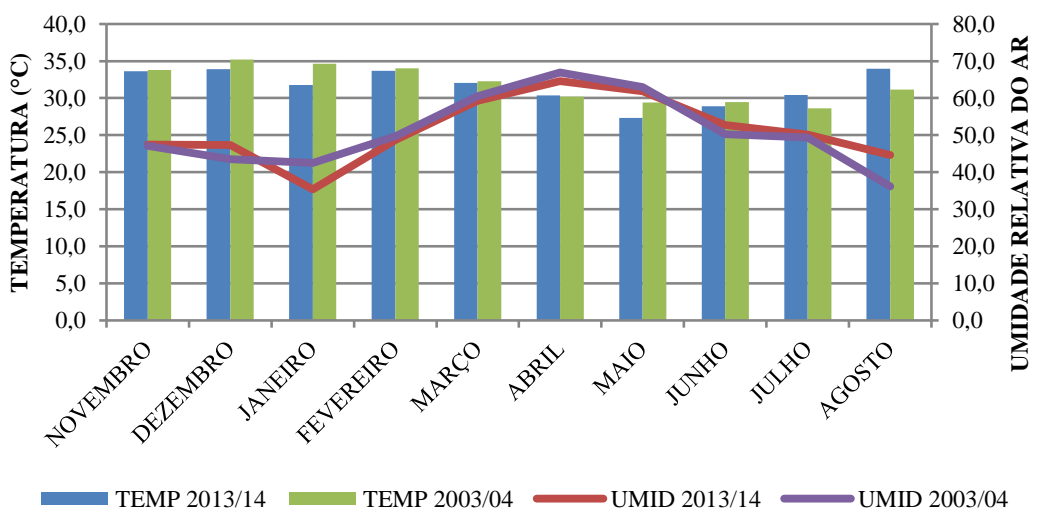


Gráfico 6 -Ponto 2 (20 horas) - relação temperatura x umidade 2003/04 e 2013/14

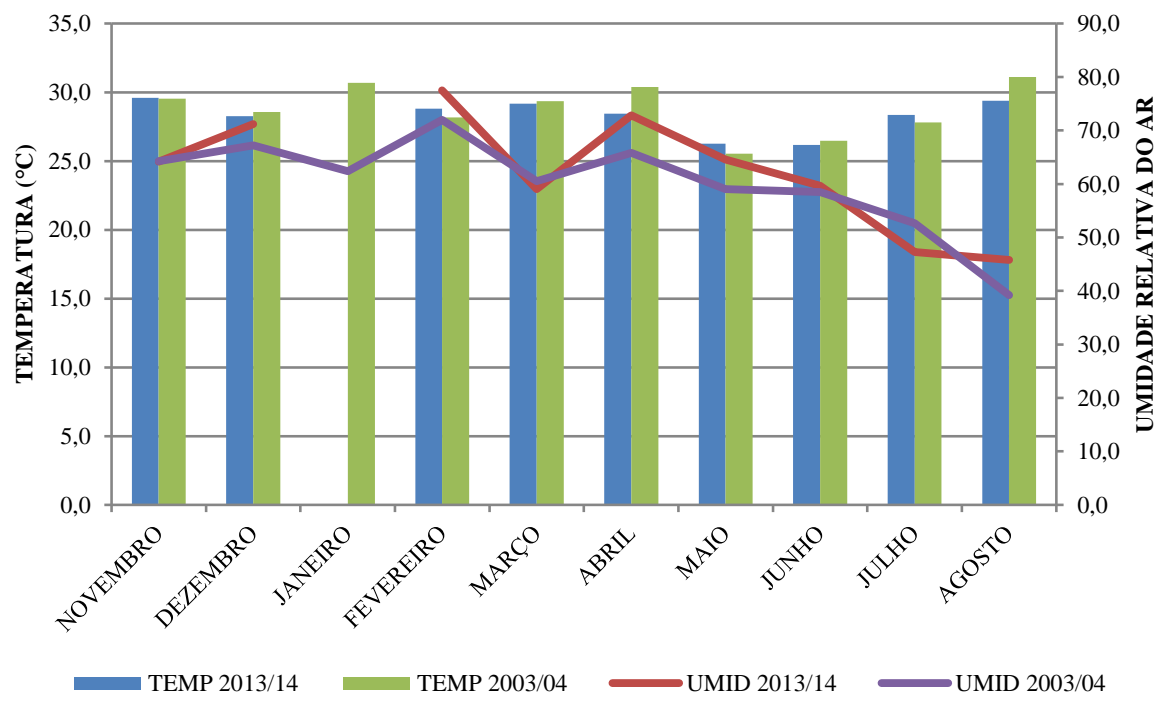

Pelo fato de pouca alteração na vegetação e ocupação do solo no local, observa-se que não houve grandes alterações no clima deste ponto.

Em 2003/04 foi registrada uma temperatura média anual de $29,7^{\circ} \mathrm{C}$ enquanto em $2013 / 14$ foi de $29,4^{\circ} \mathrm{C}$, o que representa uma variação de $0,3^{\circ} \mathrm{C}$, inferior ao que foi observado em outros pontos da cidade.

Quanto à umidade também não foi diferente, enquanto que em 2003/04 foi registrado uma média anual de $60,3 \%$, em $2013 / 14$ foi registrado uma média de $60,4 \%$, variação de apenas $0,1 \%$ em dez anos.

Segundo (BIAS et al, 2003), foi possível verificar que as ilhas de calor não se concentram somente em aras com grandes concentrações de construções, mas também, em regiões em que a vegetação original foi retirada e o solo está exposto. Esta situação se assemelha em partes com o ponto 2 deste artigo, em que nas redondezas há áreas com bastante vegetação, porém ao se aproximar da avenida esta realidade muda. Desta forma, entende-se que não basta deixar áreas permeáveis nas cidades, mas que estes locais tenham a correta arborização.

\section{Ponto 3 (Leste)}

O ponto 3 está localizado na avenida Fernando Correa da Costa, próximo à rotatória que do acesso a Universidade Federal de Mato grosso (UFMT). Neste local passam muitos veículos diariamente devido ao fato da avenida ser a principal via de acesso da região sul da cidade de Cuiabá à região central da cidade.

O local também concentra grande quantidade de estabelecimentos comerciais inclusive um shopping. Além disso a UFMT possui mais de 8000 alunos (IPDE,2007) gerando um grande fluxo de veículos e de pessoas.

Antigamente na rotatória existia uma grande concentração de vegetação (Ver figuras 12 e 13), porém para a construção de um viaduto visando melhorar a qualidade do tráfego da cidade, a vegetação da rotatória e de parte do entorno deste ponto foram removidos. 
Alves A. K.; Jesus A. T. C. de; Macêdo K. C. de; Sampaio M. de M. A.; Avaliação do Conforto Urbano Sob a Influência da Vegetação na Cidade de Cuiabá - MT. E\&S - Engineering and Science, (2017), 6:1.

Figura 12- Ponto 3- Zona Leste - Avenida Fernando Correa próximo à entrada da UFMT em 2004

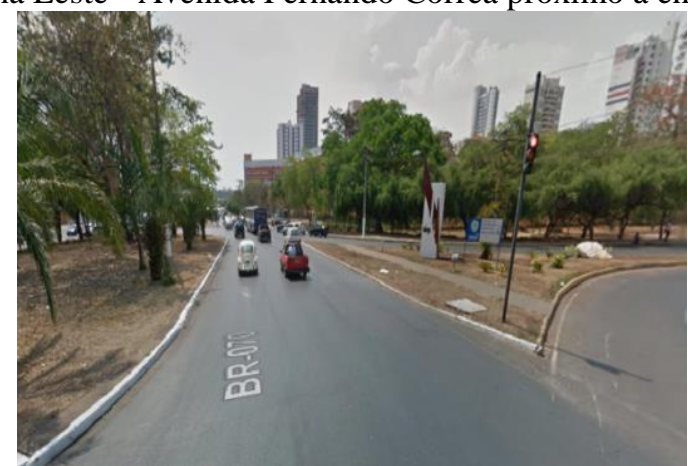

Fonte: Google Earth (acesso em 2016)

Figura 13- Ponto 3- Zona Leste - Avenida Fernando Correa próximo à entrada da UFMT em 2004

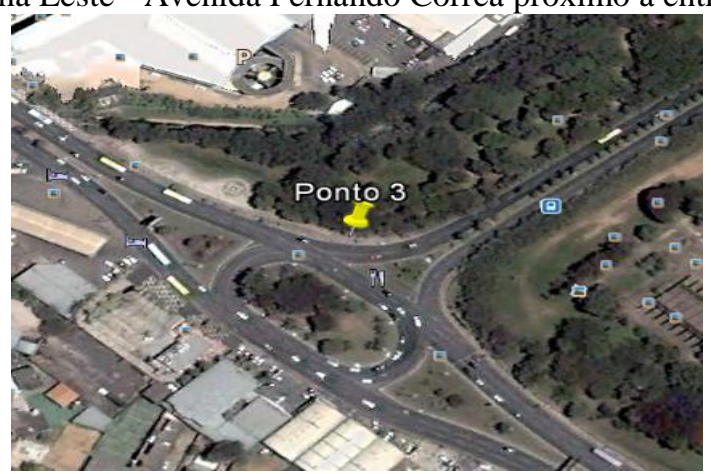

Fonte: Google Earth (acesso em 2016)

Figura 14- Ponto 3 - Zona Leste - Avenida Fernando Correa próximo à entrada da UFMT em 2014

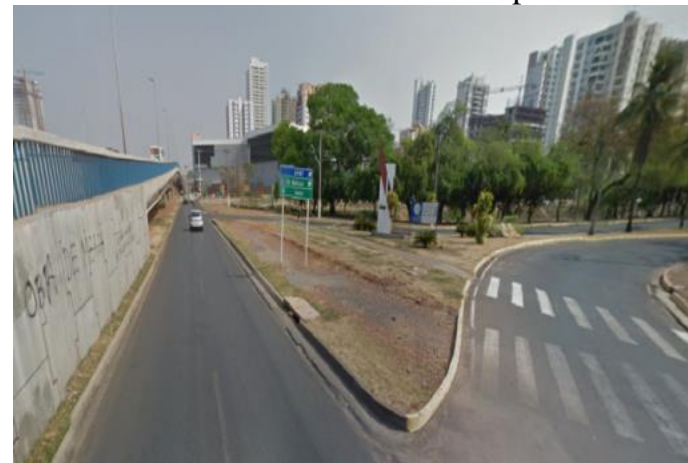

Fonte: Google Earth (acesso em 2016)

Figura 15- Ponto 3 - Zona Leste - Avenida Fernando Correa próximo à entrada da UFMT em 2014

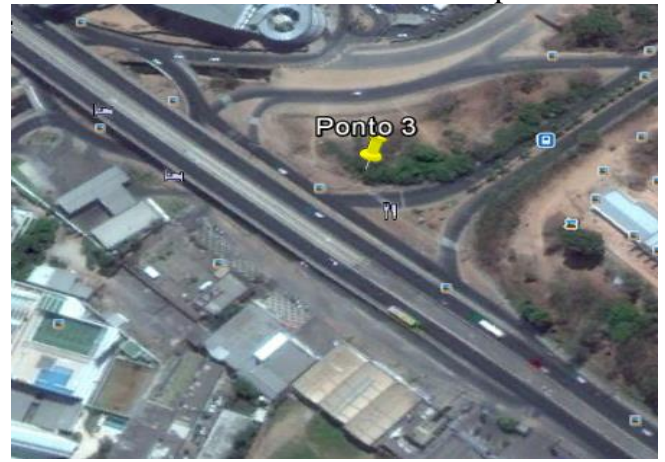

Fonte: Google Earth (acesso em 2016) 
Alves A. K.; Jesus A. T. C. de; Macêdo K. C. de; Sampaio M. de M. A.; Avaliação do Conforto Urbano Sob a Influência da Vegetação na Cidade de Cuiabá - MT. E\&S - Engineering and Science, (2017), 6:1.

Gráfico 7 -Ponto 3 (8 horas) - relação temperatura x umidade 2003/04 e 2013/14

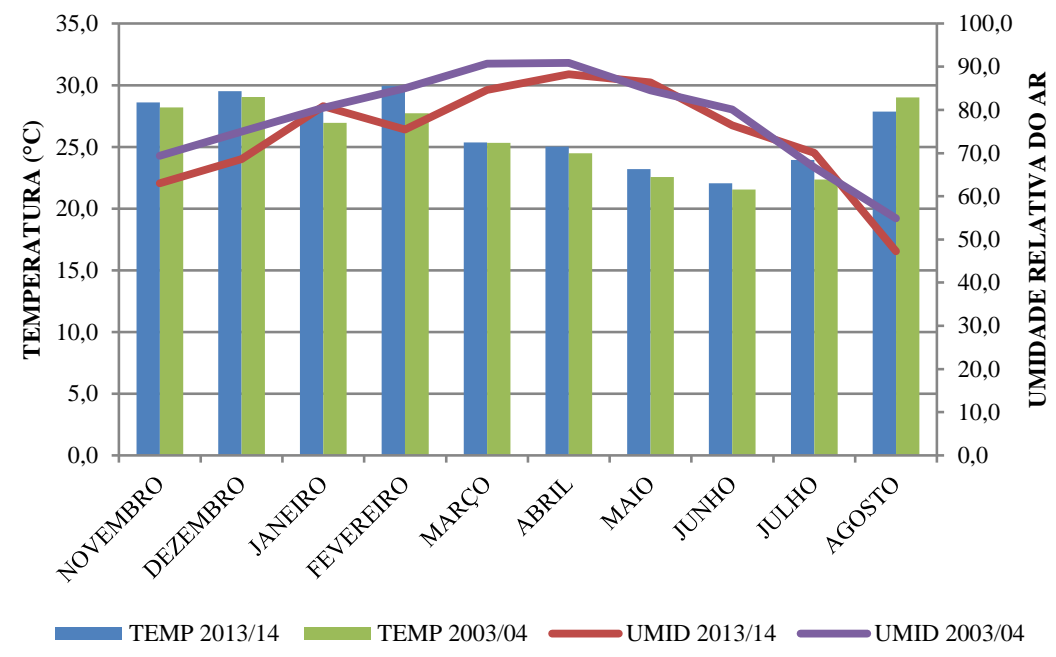

Gráfico 8 - Ponto 3 (14 horas) - relação temperatura x umidade 2003/04 e 2013/14

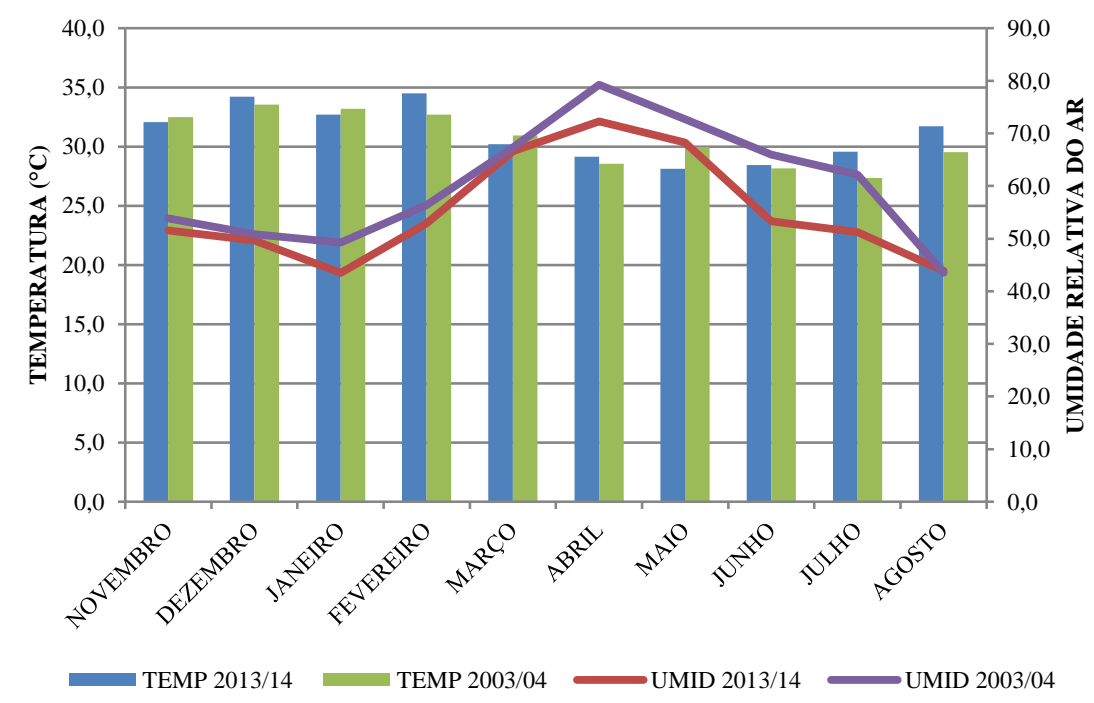

Gráfico 9 - Ponto 3 (20 horas) - relação temperatura x umidade 2003/04 e 2013/14

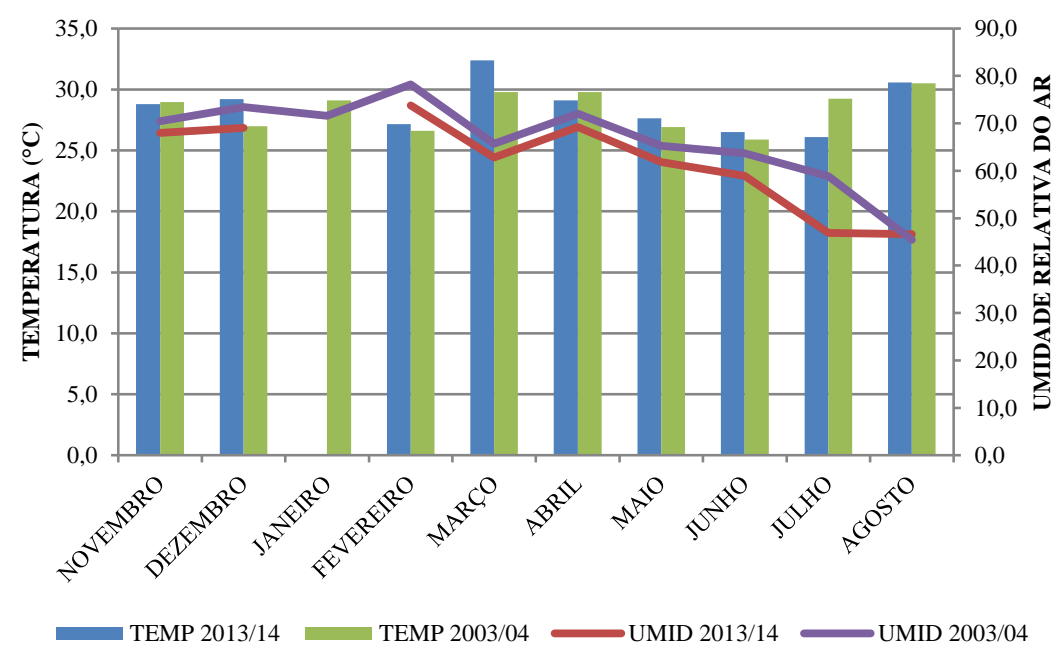


Alves A. K.; Jesus A. T. C. de; Macêdo K. C. de; Sampaio M. de M. A.; Avaliação do Conforto Urbano Sob a Influência da Vegetação na Cidade de Cuiabá - MT. E\&S - Engineering and Science, (2017), 6:1.

Analisando os gráficos percebe-se que de modo geral a temperatura aumentou e a umidade do ar diminuiu de 2003/04 para 2013/14.

Segundo os dados coletados observou-se um aumento de aproximadamente $0,6^{\circ} \mathrm{C}$ na média da temperatura anual, isso ocorreu provavelmente pelo fato da remoção da vegetação e posterior substituição por concreto próximo ao local de coleta de dados. Em relação ao horário, a maior variação de 2003/04 para 2013/14 foi no período da manhã, com um aumento de $0,9^{\circ} \mathrm{C}$ em dez anos.

A umidade do ar teve um resultado contrário ao da temperatura, com uma redução significativa de $4,2 \%$ no mesmo período.

Percebe-se que no ponto 3 há espaço para implantação de praças públicas e plantio de árvores de forma que minimizem o desconforto térmico e contribua para a integração do espaço urbano com a vegetação.

Segundo (GOMES, AMORIM, 2006), as praças públicas devem ser dotadas de infraestrutura básica como parque infantil, bancos com encosto, calçadas e iluminação eficiente. Devem ainda ocupar espaço significativo como o de uma quadra (10.000 m2 ) e não apenas alguns poucos metros quadrados. Consequentemente, podem abrigar espécies arbóreas de médio e grande porte como o ipê-roxo (Tabebuia impetiginosa) e a sibipiruna (Caesalpiniapeltophoroides), além do pau d'alho (Gallesiaintegrilolia) e do flamboyant (Delonix regia); Essas espécies reduzem eficientemente a radiação solar devido ao sombreamento que provocam.

\section{Relação da Vegetação e da Temperatura Local}

As árvores representam um elemento chave para um desenho adequado às exigências de conforto. A vegetação possui uma importante função na melhoria e estabilidade microclimática devido à redução das amplitudes térmicas, redução da insolação direta, ampliação das taxas de evapotranspiração e redução da velocidade dos ventos (MILANO, DALCIN, 2000).

Os benefícios da arborização são tão mais necessários à saúde ambiental do ecossistema urbano, quanto maior for a sua urbanização (MENEGHETTI, 2003).

Segundo a pesquisa realizada na cidade de Cuiabá por Oliveira (2011) sobre a influência da vegetação arbórea no microclima e uso de praças públicas, revelou que, regiões mais arborizadas e com sombra densa, apresentaram menores valores de temperatura superficial, quando comparados com aquelas não arborizadas. Além disso, locais com concentração de espécies como mangueiras e oitis, espécies descritas por diversos autores por suas qualidades positivas de sombreamento, de fato apresentaram melhores resultados na redução da temperatura do local. Em contrapartida, palmáceas que apresentam pequenas copas e grandes alturas de fuste não apresentou boa qualidade de sombreamento.

O desafio das grandes cidades é o crescimento e o desenvolvimento urbano que proporcionem geração de riqueza, qualidade de vida e qualidade ambiental para seus atuais e futuros habitantes. Esse é o princípio do desenvolvimento sustentável, o qual estabelece o meio ambiente como ponto comum e de equilíbrio entre a tecnologia e o progresso, na escala onde a vida acontece: o espaço urbano. (ARAUJO, CARAM, 2006)

\section{CONSIDERAÇÕES FINAIS}

A formação dos ambientes térmicos urbanos está diretamente associada aos aspectos da morfologia do seu entorno. (SAMPAIO, 2015)

Foi evidenciado pelos resultados obtidos que, a variação na temperatura está diretamente ligada com a vegetação existente no local. $\mathrm{O}$ ponto 3 foi um local onde houve 
Alves A. K.; Jesus A. T. C. de; Macêdo K. C. de; Sampaio M. de M. A.; Avaliação do Conforto Urbano Sob a Influência da Vegetação na Cidade de Cuiabá - MT. E\&S - Engineering and Science, (2017), 6:1.

uma grande transformação da paisagem da região, e por consequência uma alteração na temperatura e umidade local de forma negativa. Em contrapartida o ponto 2 não sofreu significativas alterações na urbanização local, o que fez com que mesmo após dez anos os resultados permanecessem quase inalterados.

O ponto 1 desde muito tempo é uma região bem urbanizada, porém nos últimos anos cresceu ainda mais o índice de urbanização reduzindo áreas permeáveis e vegetadas. Estes fatores influenciassem no incremento da temperatura desta região.

A arborização urbana humaniza os espaços e, num país tropical como o Brasil, as árvores são muito importantes por sua capacidade de redução do calor excessivo, da incidência solar direta e de golpes de ventos (STRINGHETA, 2005).

Algumas pesquisas indicam que certas espécies de árvores geram maior sombra e conforto ambiental, além de contribuem para o paisagismo local, logo cabe a cada cidade ou região selecionar as espécies que melhor se adaptam ao seu clima, e fazer o melhor planejamento urbano possível visando não somente a questão visual, mas também o conforto ambiental.

\section{REFERÊNCIAS}

ACSELRAD, Hi. Discurso da sustentabilidade urbana. Anais: Encontros Nacionais da ANPUR, v.8 2013.

AMORIM, M. C. C. T. Climatologia e gestão do espaço urbano. Mercator, Fortaleza, número especial, p. 71-90. 2010.

ARAUJO, B. C. D; CARAM, R. Análise ambiental: estudo bioclimático urbano em centro histórico. Ambiente \& Sociedade - Vol. IX nº , 2006. p. 149-167.

BERTELLO, E. Minimanual de Pesquisa em Geografia. Uberlândia, Minas Gerais, Editora Claranto, 2004.

BIAS, E. S. atal, Análise do fenômeno de ilhas de calor urbanas, por meio da combinação de dados Landsat e Ikonos. Anais XI SBSR, Belo Horizonte, 10 de abril de 2003.

BONAMETTI, João Henrique. Arborização urbana. Terra, 2001.

BRITO,P. A dinâmica do processo de urbanização no Brasil, 1940-2010. disponível em (http://www.abep.nepo.unicamp.br/xviii/anais/files/POSTER[672]ABEP 2012.pdf). Acesso em Fevereiro de 2016.

CARVALHO, M. E. C. As áreas verdes de Piracicaba. Dissertação (Mestrado em Geografia) Instituto de Geociências e Ciências Exatas, Universidade Estadual Paulista. Rio Claro, 1982.

CORBElla, O. D.; MAGAlHÃES, M. A. A. A. Conceptual differences between the bioclimatc urbanism for Europe and for the tropical humid climate. Renewable Energy, 2008, v.33, p. 1019-1023, 2008.

EMBRAPA. 
Alves A. K.; Jesus A. T. C. de; Macêdo K. C. de; Sampaio M. de M. A.; Avaliação do Conforto Urbano Sob a Influência da Vegetação na Cidade de Cuiabá - MT. E\&S - Engineering and Science, (2017), 6:1.

GOMES, M. A. S.; AMORIM, M. C.C. T. Arborização e conforto térmico no espaço urbano: estudo de caso nas praças públicas de Presidente Prudente (SP). Caminhos de Geografia, v. 4, n. 10, 2006.

GUARIM, G.N. Diagnóstico florístico e faunístico da cidade de Cuiabá . Cuiabá: Universidade Federal de Mato Grosso/Prefeitura Municipal de Cuiabá, 1990. 190 p. (Relatório de Pesquisa).

HOUAISS, A.; VILLAR, M. S. Dicionário Houaiss de Língua Portuguesa. Elaborado pelo Instituto Antônio Houaiss de Lexicografia e Banco de Dados da Língua Portuguesa S/C Ltda. Rio de Janeiro: Objetiva, 2009.

IBGE - Instituto Brasileiro de Geografia e Estatística. Disponível em: <http://www.ibge.gov.br>. Acesso em: Fevereiro de 2016.

IPDU - Instituto de Planejamento e Desenvolvimento Urbano: Disponível em: <http://www.cuiaba.mt.gov.br/upload/arquivo/perfil_socioeconomico_de_cuiaba_Vol_III.pdf $>$.

KATZCHNER, L. "Urban climate studies as tools for urban planning and architecture", in: Encontro Nacional de Conforto no Ambiente Construído, 4o, Salvador, 1997. Anais... Salvador: FAU/UFBA, ANTAC, p. 49-58.

MAITELLI, G. T. - Uma abordagem tridimensional de clima urbano em área tropical continental: o exemplo de Cuiabá-MT. São Paulo, FFLCH-USP, 1994. Tese (Doutorado em Geografia). Faculdade de Filosofia, Letras e Ciências Humanas, Universidade de São Paulo, 1994.

MENEGHETTI, G. I. P. Estudo de dois métodos de amostragem para inventário da arborização de ruas dos bairros da orla marítima do município de Santos, SP. 2003, 100p. Dissertação (Mestrado em Ciências Florestais) - Escola Superior de Agricultura "Luiz de Queiroz”, Universidade de São Paulo, Piracicaba, 2003.

MEMON, R. A.; LEUNG, D. Y. C.; CHUNHO, L.A review on the generation, determination and mitigation of Urban Heat Island. Journal of Environmental Sciences, Beijing, v. 20, p. 120-128, 2008.

MILANO, M. S.; DALCIN, E. C. Arborização de vias públicas. Rio de Janeiro, RJ: Light, 2000. 131p.

MONTEIRO, C. A. F. Por um suporte teórico e prático para estimular estudos geográficos do clima urbano no Brasil. Geosul, Florianópolis, 1990, v.5, n.9, p. 7-19.

OKE, T. R. The energetic basis of the urban heat island. Quart.Journal. Roy. Met. Soc., 1982, p. $1-24$.

OLIVEIRA, A. S. Influência da vegetação arbórea no microclima e uso de praças públicas, Cuiabá, MT. 2011, pg 130. Tese (Doutorado) - Universidade Federal de Mato Grosso. Cuiabá, 2011. 
Alves A. K.; Jesus A. T. C. de; Macêdo K. C. de; Sampaio M. de M. A.; Avaliação do Conforto Urbano Sob a Influência da Vegetação na Cidade de Cuiabá - MT. E\&S - Engineering and Science, (2017), 6:1.

SAMPAIO, M. M. A. Transformações microclimáticas e legislação: O caso de Cuiabá-MT. Tese (Doutorado), Faculdade de Arquitetura e Urbanismo (FAU), Universidade Federal de Mato Grosso. Cuiabá, 2015.

STRINGHETA, A.C.O. Arborização urbana no Brasil. Revista Ação Ambiental, Viçosa, v. 8, n. 33, p. 9-11, set./out. 2005. 